\title{
Tridimensional photographic reconstruction in a study of the pathogenesis of honeycomb lung
}

\author{
J. C ORTEZ PIMENTEL
}

\author{
From I.A.N.T. (Department of Pathology, Sanatorium D, Carlos I) and the Institute of Pathology, \\ Faculty of Medicine, University of Lisbon, Portugal
}

\begin{abstract}
Tridimensional photographic reconstruction of the lesions found in honeycomb lung in 10 different types of pulmonary disease was made. The pathological picture was characteristic and well defined by tridimensional microscopy and quite independent of the accompanying disease. The lesions responsible for its appearance involved the whole lobular bronchiolar system but were most marked in the terminal and respiratory bronchioli. The changes were fundamentally diffuse, saccular, and cystic bronchiolectasis. Other bronchiolar lesions were found such as changes in direction and mode of division, amputations, and anastomoses between bronchioles and cysts belonging to anatomically independent airways. There was some evidence that the bullous aspects of honeycomb lung were due to multiple valvular arrangements which let the air in but do not let it out. Honeycomb lung was, in the majority of cases, a complication of interstitial pulmonary fibrosis. Honeycombing was usually due to marked changes in the lobular bronchioles caused by the obliteration or rigidity of alveolar ducts and the corresponding alveoli and even by localization of the interstitial fibrosis in the bronchiolar wall.
\end{abstract}

The term 'honeycomb lung' (Hyde, Hyde, and Pokorny, 1951; Heppleston, 1956) has been applied to a pulmonary lesion characterized by the presence of multiple cystic cavities with average diameters between 1 and $10 \mathrm{~mm}$. These cysts, microscopically, are bronchiolar dilatations with a well-defined wall made up of scar tissue or of a granulomatous process of varied aetiology (Heppleston, 1956).

This lesion can be diffuse or localized and is usually found in certain diseases that predominantly involve the alveolar septa: sarcoidosis (Nickerson, 1937), berylliosis (Dutra, 1948), asbestosis (Telischi and Rubenstone, 1961), eosinophilic granuloma of the lung (Auld, 1957), Abt-LettererSiwe disease (van Creveld and ter Poorten, 1935), Hand-Schuller-Christian disease (Keats and Crane, 1954), diffuse scleroderma (Mahrer, Evans, and Steinberg, 1954), rheumatoid arthritis (Rubin, 1955), dermatomyositis (Mills and Mathews, 1956), some cases of progressive pulmonary fibrosis-Hamman-Rich syndrome (Peabody, Buechner, and Anderson, 1953), and tuberculosis (Buechner and Anderson, 1955). Some authors consider it a consequence of interstitial pulmonary fibrosis (Anderson and Foraker, 1960 ; Pimentel, 1962). Honeycomb lung is also part of the morphological picture of a rare pulmonary $\overline{\bar{\partial}}$ disease known as cystic cirrhosis of the lung (von Buhl, 1872), pulmonary muscular hyperplasia (Rubenstein, Gutstein, and Lepow, 1955), bronchiolar emphysema (Siebert and Fisher, 1957), and $\vec{\partial}$ diffuse pulmonary leiomyomatosis (Delarue, Paillas, Paley, Daumet, and Daussy, 1960).

Numerous theories have been proposed to 3 explain the genesis of honeycomb lung. Heppleston (1956), using microdissection and the study 3 of serial histological sections, thought that 0 obliteration or dilatation of the respiratory bronchioles was the essential change in theo disease. According to this author, unaffected adjacent bronchioles underwent a compensatory $\mathscr{N}$ dilatation, thus forming cystic cavities near con- N solidated and fibrotic areas. Heppleston alsoN believed that the progressive enlargement of the ${ }_{\sigma}^{\omega}$ cysts was probably due to secondary valvular obstruction of the bronchioles that communicated? with them.

Siebert and Fisher (1957), on the other hand, believed that a "congenital hypoplasia of the distal segment of the respiratory unit' was the cause of the honeycomb lesions in 'pulmonary muscular $\frac{\rho}{\mathbb{D}}$ cirrhosis'. González-Licea and Perez-Tamayo 음 (1963) disagreed with Siebert and Fisher's theory 
as they found it to be based on erroneous dataimproper fixation of the lungs and difficulty in distinguishing respiratory bronchioles, bronchiolar alveoli, alveolar ducts, and ductal alveoli in these severely altered lungs. These authors thought that in muscular cirrhosis of the lung the lesions acquired diffuse bronchiolectasis secondary to chronic infection, and that Heppleston's theory was still the one that best explained honeycombing.

The methods used up to now, such as microdissection and serial sections, do not permit any further advances in our knowledge of the pathogenesis of honeycomb lung. The "bronchovascular cast' technique which we tried out gave no better results, so we experimented with tridimensional reconstructions from photographic enlargements of serial sections of the lesions. In this paper possible applications of this method in the study of honeycomb lung are presented.

\section{MATERIAL AND METHODS}

Models were constructed of the honeycomb lesions found in the following diseases: diffuse scleroderma, dermatomyositis, Abt-Letterer-Siwe and Hand-Schuller-Christian diseases, progressive pulmonary fibrosis (Hamman-Rich syndrome), muscular cirrhosis of the lung, sarcoidosis, and diffuse fibrotic tuberculosis. Honeycombing of a purely local character, formed near tuberculomas and foci of endogenous lipoid pneumonia, was studied by the same method, as well as some lobular bronchiolar systems of three normal lungs. In eight cases the reconstructions were made from necropsy material, and in three from surgical specimens. The lungs were fixed by low-pressure intrabronchial instillations of a $10 \%$ aqueous solution of formalin until a uniform distension of the pleura was obtained.

One case of each of the diseases mentioned was studied. From each case three of the most representative lesions were chosen, with a surface area of about $5 \times 3 \times 2 \mathrm{~cm}$. These were embedded in paraffin, and serial sections were made which were then stained with haematoxylin and eosin. The number of sections studied from each block was between 100 and 250 .

Reconstruction was made from microphotographs of the serial sections using enlargements of $\times 125, \times 170$, or $\times 250$, according to the need for more or less detail. Kodak 0.250 Rapid Orthochromatic metalographic plates and Gevatone $\mathrm{k} 3$, grade $2,30 \times 40 \mathrm{~cm}$. Gevaert paper were used. A green filter was used to improve the contrast of the red stains. The photographs were stuck on compressed cardboard of a thickness related to the enlargement.

Of each group of photographs corresponding to a certain lesion, models in 'positive' and 'negative' were constructed so that not only the bronchiolarcystic connexions could be noted but also the topography of the bronchiolar lesion. The irregular staircase effect caused by the superimposition of the different layers was reduced by applying a thin coat of synthetic filler.

\section{RESULTS}

Tridimensional reconstruction of the bronchioles according to the method described made it relatively easy to study their course, calibre, and manner of division in the diseased areas, and also to appreciate their intimate relations with the cysts. The results obtained with this method in the study of honeycomb lung seemed superior to those so far obtained in alveolar emphysema, probably because the size of the air spaces and the histological structure of their walls are fundamentally different in the two conditions.

It has been stated that in severely damaged lungs, such as in honeycomb lungs with extensive fibrosis, it is difficult to distinguish respiratory from non-respiratory bronchioles. Although it may be difficult, usually it is not so if one keeps in mind the classical bronchiolar distribution (Miller, 1947 ; von Hayek, 1960), uses large sections and adequate photographic enlargements, and compares them with reconstructions of normal bronchioles. The data obtained from tridimensional reconstruction of the honeycomb lesions in all the types of disease studied were identical and as such will be described together. The bronchiolar changes were particularly obvious in the fibrocystic areas, even though they might have been found outside them. They involved the lobular bronchioles electively. The changes are described at three different levels: non-respiratory bronchioles, respiratory bronchioles, and the alveolar ducts and alveoli.

NON-RESPIRATORY BRONCHIOLES The changes generally involve most of the non-respiratory portion of the lobular bronchiolar system, but are especially found in the distal divisions of the lobular bronchiole and in the terminal bronchioles. These changes consist of diffuse and segmental (frequently cystic) dilatation, bronchiolar irregularities, changes in the usual bifurcation angles and, more rarely, amputations (Figs $1 B$ and $2 B$ ). In the latter case the non-respiratory bronchioles, 


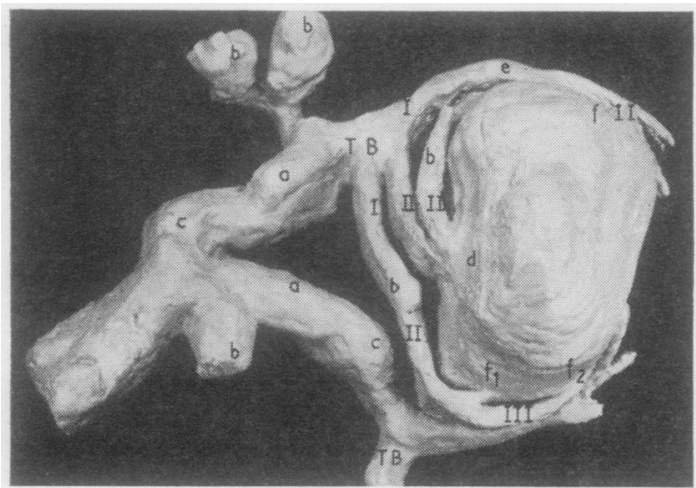

FIG. 1. (A) Part of a honeycomb lung in a case of Hamman-Rich syndrome. $\times 16$. $(B)$ 'Negative' tridimensional reconstruction of the area marked by the circle (original $\times 25$ ). The non-respiratory bronchioles showed dilatations $(a)$, amputations $(b)$, and angulations $(c) ;$ in the respiratory bronchioles, the oblique disposition of the $\overrightarrow{\vec{D}}$ afferent bronchiole $(d)$, the circular disposition of the bronchioles around the cyst $(e)$, and various anastomoses $(f, f 1, f 2)$ are shown. $T B$, terminal bronchiole; $I, I I$ and III, first, second, and third respiratory bronchioles. (C) 'Positive' reconstruction of the opening of the afferent bronchiole (probable valve mechanism marked with an arrow). Original size $\times 75$.

(B)

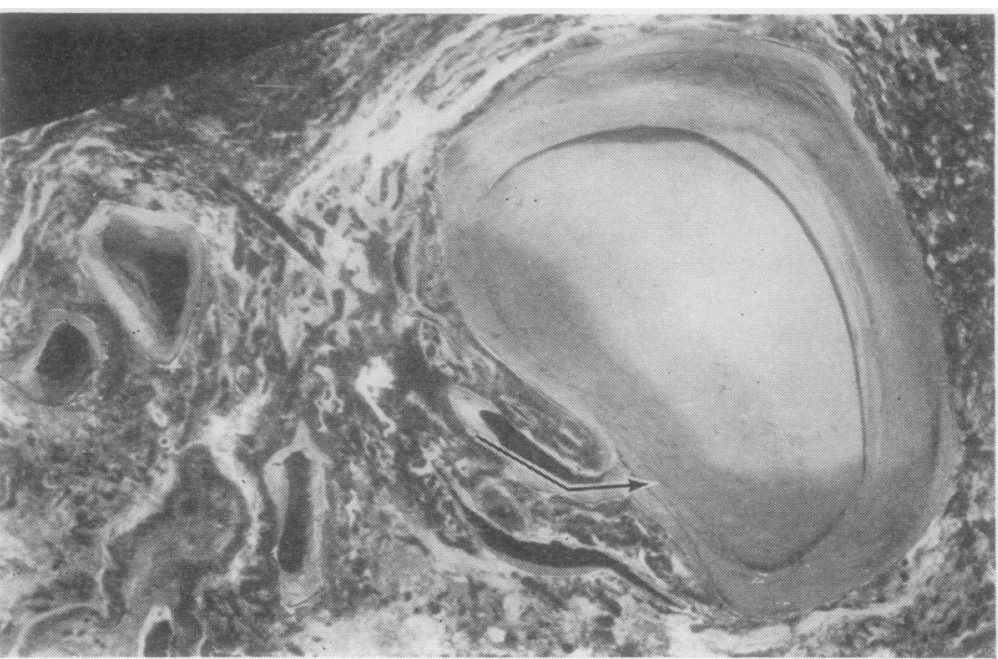




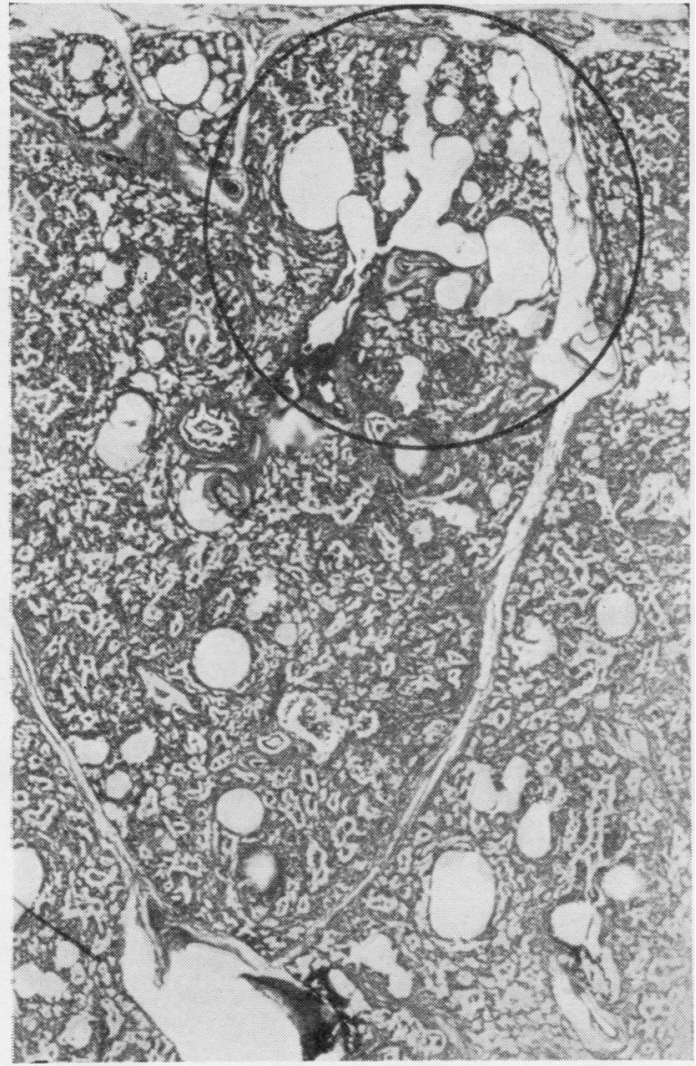

(A)

after a rather extended course, finish in a cul-desac which may take various forms.

In this sector the frequent absence of easy communication between the segmental bronchiolar dilatations, whatever their form, should be stressed. In most of the models little tongues of pulmonary tissue could be seen at the bronchiolocystic junctions. These probably act as valves making the exit of air difficult.

RESPIRATORY BRONCHIOLES The changes are varied and considerable, frequently appearing simultaneously (Fig. 6B). They consist of an appreciable change in the direction and division of the bronchioles, an irregular sometimes sinuous course, the presence of amputations, and especially dilatation and formation of cystic cavities (Figs 1B, 2B, 3B, 4B, 4C, and 5B).

The changes in the usual disposition of the bronchioles are sometimes so great that they have probably undergone rotations of nearly $90^{\circ}$. The angles of division are also frequently very acute

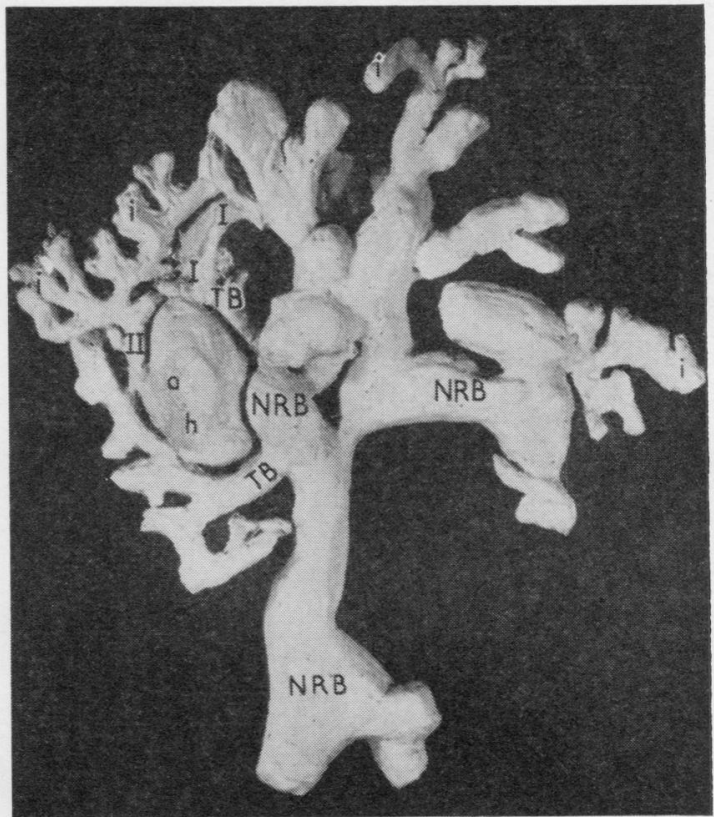

(B)

FIG. 2. (A) Lobule of honeycomb lung in a case of AbtLetterer-Siwe syndrome. $\times 15$. (B) Tridimensional reconstruction of the marked area. Diffuse dilatations involving respiratory $(T B, I, I I)$ and non-respiratory $(N R B)$ bronchioles; cyst with afferent bronchiole placed tangentially (d) and relatively normal but displaced afferent bronchioles $(h) ;$ alveolar ducts turned into large sacs (i). Original size $\times 32$.

(Figs 1B and 2B). In contrast with the nonrespiratory bronchioles, amputations are frequent in this sector (Fig. 1B). All these changes may involve first and second order bronchioles and probably those of the third order. They may present two different appearances: sometimes they constitute a long, straight or slightly wavy, regular or rat-tailed cul-de-sac (Fig. 1B); at others they form small, irregular, hour-glass, gourd or starshaped cavities. The latter type of bronchiolar dilatations generally communicate freely with the respiratory bronchiole from which they originate. They sometimes are formed at the amputation of a common bifurcation.

The cysts, in our reconstruction, are frequently found at the distal ends of first and second order respiratory bronchioles (Figs $1 \mathrm{~B}$ and 4B). Evidence that some of the larger cystic cavities are the result of global dilatation of first and second order bronchioles comes from the finding of vestiges of bifurcation spurs, and comparison with models of normal bronchioles. 


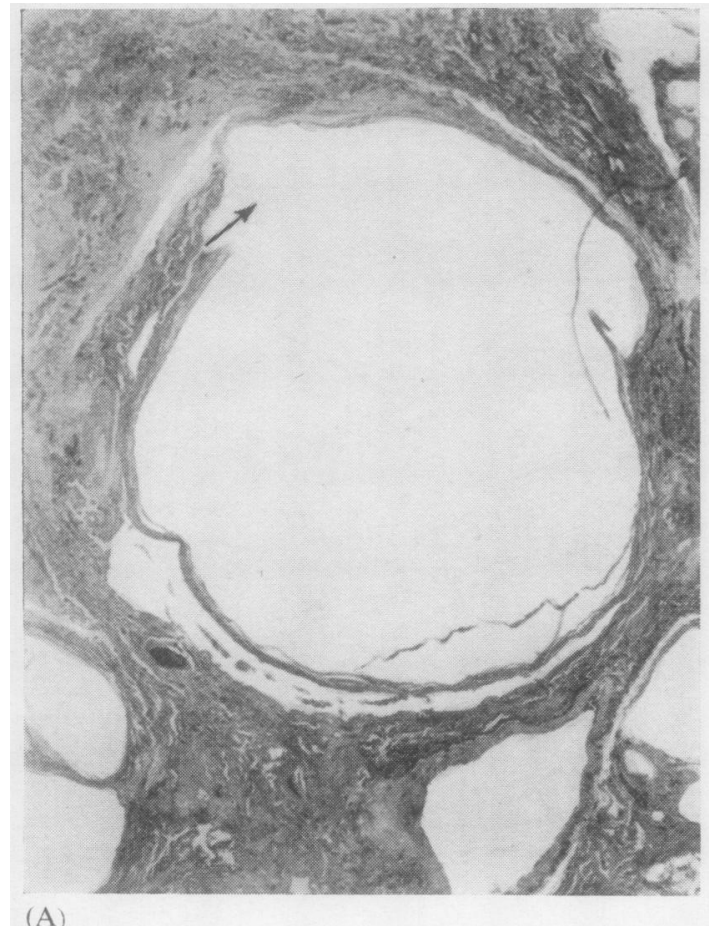

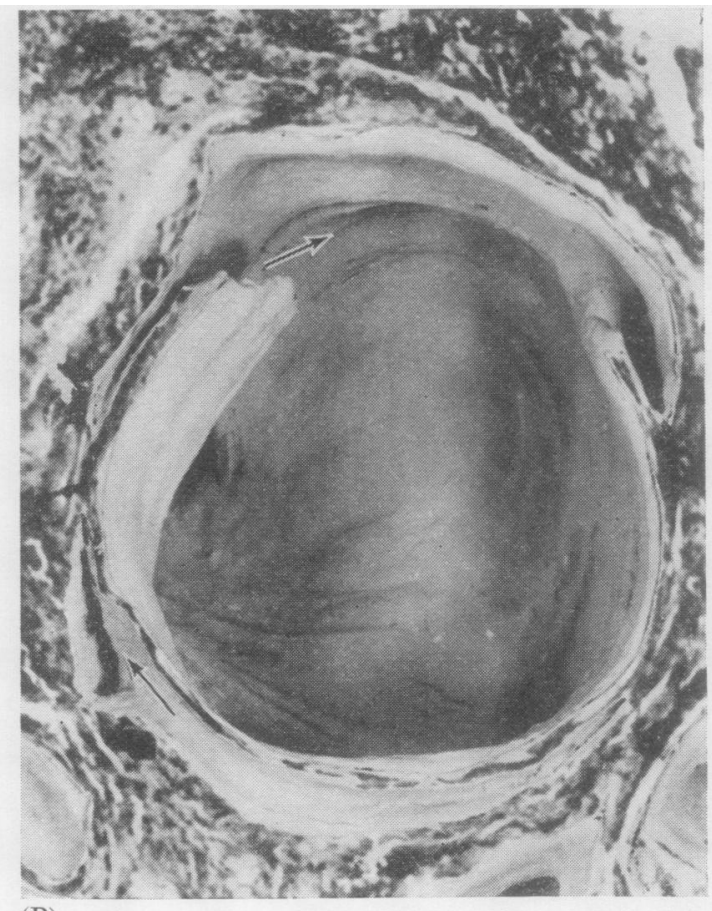

(B)

FIG. 3. (A) Detail of a cyst in a case of pulmonary muscular cirrhosis. The opening of the bronchiole (arrow) suggests a valve mechanism. $\times 14$. $(B)$ Tridimensional reconstruction of the area shown in $(A)$. Note the tangential and oblique disposition of the afferent bronchiole and its opening into the cyst. This view emphasizes the difficulties for the outflow of air. Original size $\times 16$.

The size and number of cysts in the same system are variable. In some there is a single cyst (Figs $1 \mathrm{~B}$ and $2 \mathrm{~B}$ ), whereas in others numerous cysts are arranged along the bronchiolar branches like bunches of grapes (Figs 4B and 5B).

On studying the relationship between respiratory bronchioles and cystic cavities we noticed that, whereas some communicated freely, others presented valvular arrangements similar to those described in the non-respiratory bronchioles, and in others the afferent bronchiole was straight and narrow and opened in the cyst obliquely or tangentially (Figs 1B, 1C, 3B, 4C, and 4D). This latter finding was noted in a large number of cysts in all the conditions studied and exists in both solitary and multiple cysts. Figure $5 \mathrm{C}$ is a diagram of a plan of one of our models from a case of scleroderma and illustrates this suggested valve mechanism.

The cysts are often formed near the bifurcation of two respiratory bronchioles, one branch of which continues, and are surrounded by the other and its own branches which adapt to the cystic surface, forming an almost complete ring around it (Figs 1B and 2B). These bronchioles have a narrowed lumen, and after a variably extended course may penetrate the cystic cavity, either obliquely or tangentially (Fig. 1B).

Besides these anastomoses between the cysts and one or more respiratory bronchioles, which are the result of the division of one of the branches of a terminal bronchiole, similar changes may also be noted in between the respiratory bronchioles coming from the other branches of the terminal bronchioles. These anastomoses are very frequent findings in reconstructions of cystic lesions in the respiratory bronchiolar portion of honeycomb lung.

Finally, it was noted that the bronchioles beyond the cysts may present two different appearances: sometimes they are relatively well preserved although altered in various ways, especially their relative positions; at others they are reduced to a small cul-de-sac or to two short, irregular, and slightly distorted ramifications.

ALVEOLAR DUCTS AND ALVEOLI The changes in this sector could not be studied with the same 


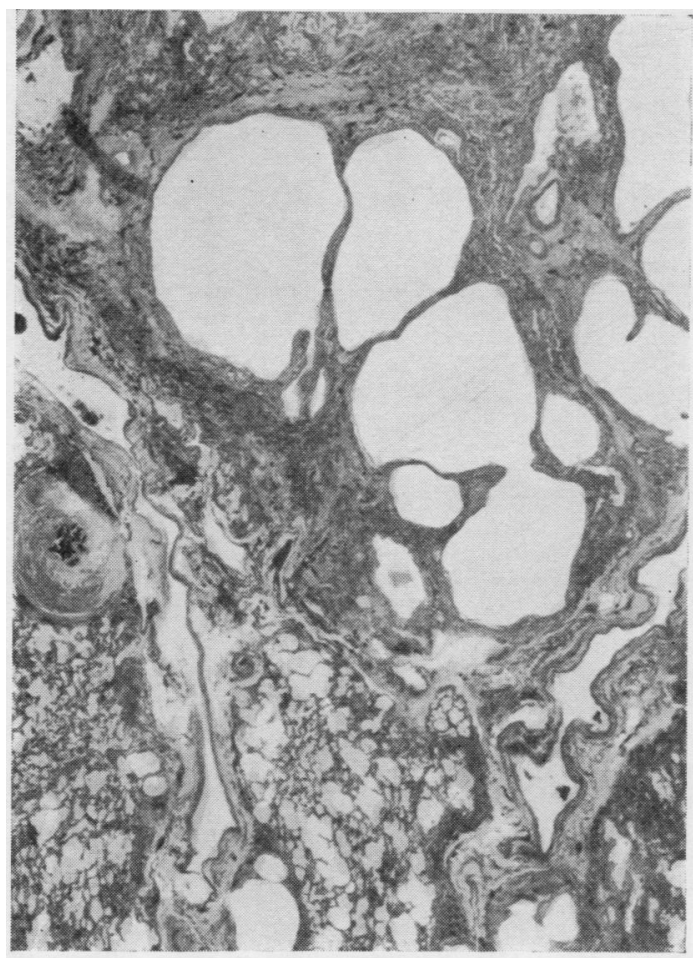

(A)

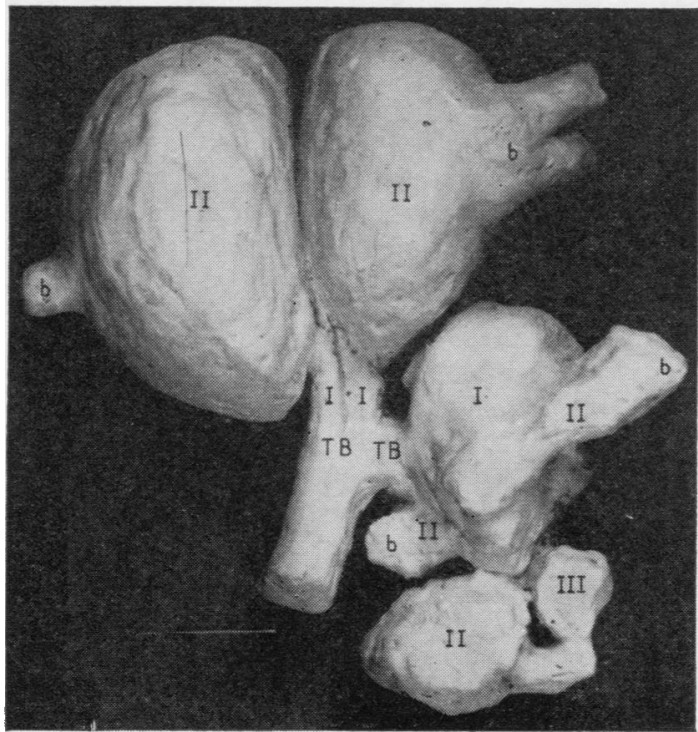

(B)

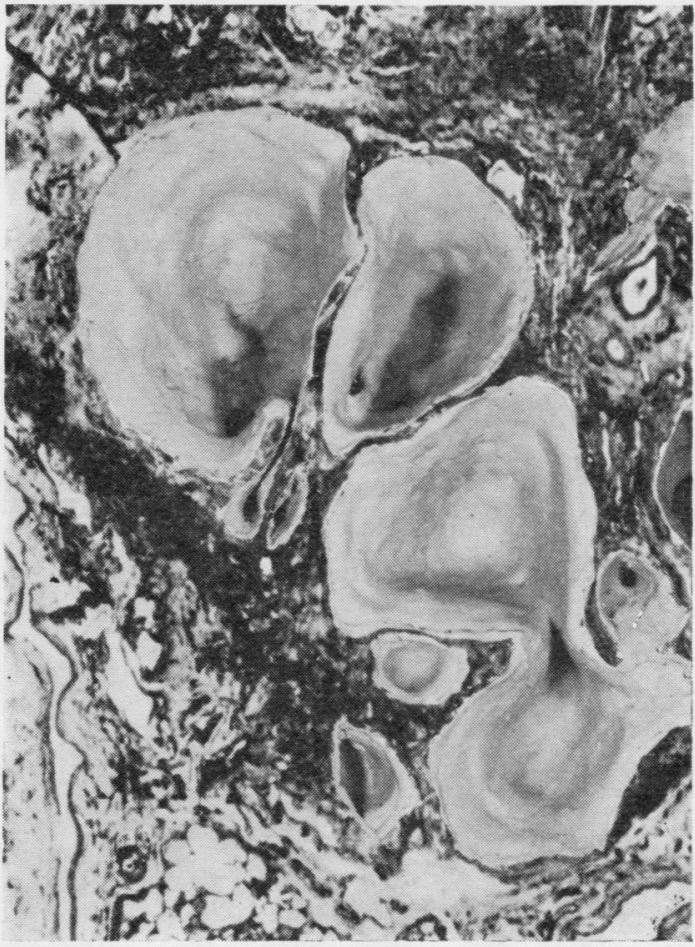

(C)

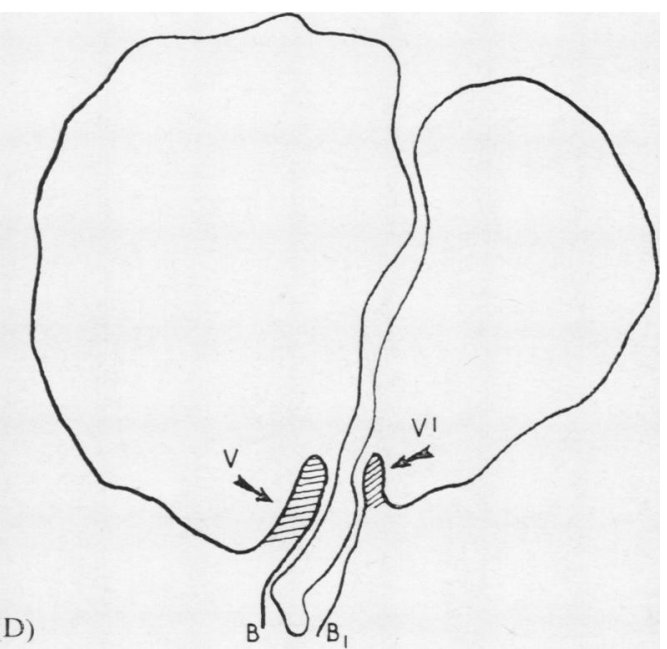

FIG. 4. (A) General view of a cluster of cysts in a honeycomb lung in a case of sarcoidosis. $\times 11$. (B) Tridimensional reconstruction in 'negative'. Note the amputations in the efferent bronchioles of the cysts $(b)$. Original size $\times 14$. $(C$, Tridimensional reconstruction in 'positive'. The afferent bronchioles of the cysts $\left(B\right.$ and $\left.B_{1}\right)$ are tangential and have flute-like openings. Original size $\times 16$. (D) Diagram of the 'valve mechanisms' shown in $(A)$ and $(C)$. 


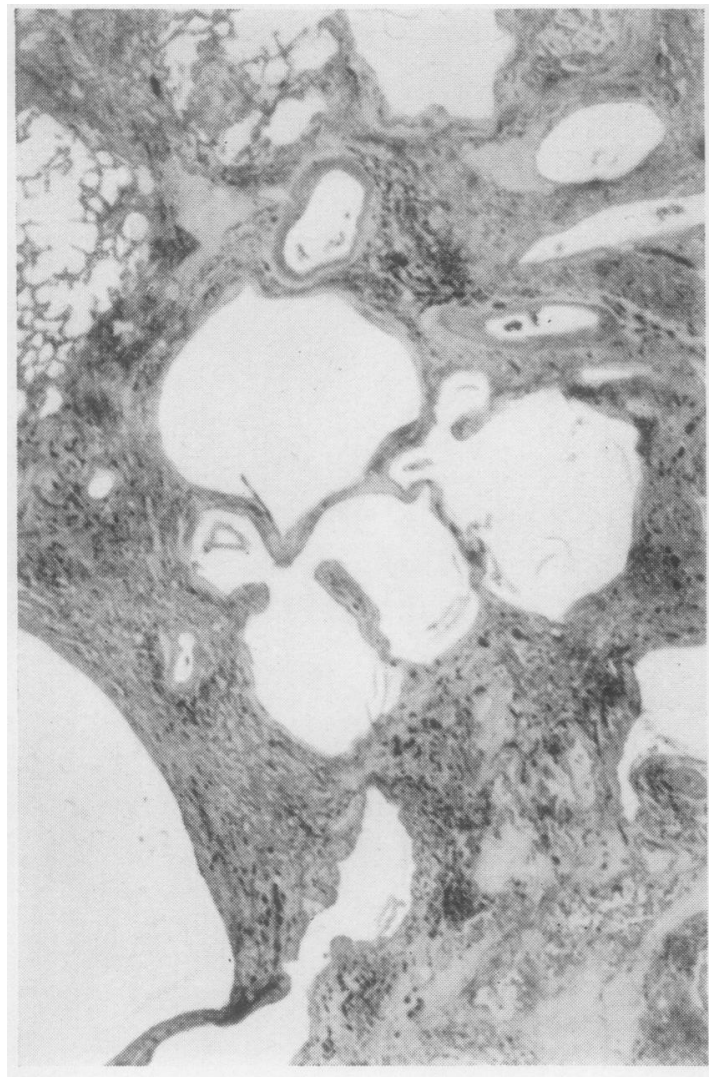

(A)

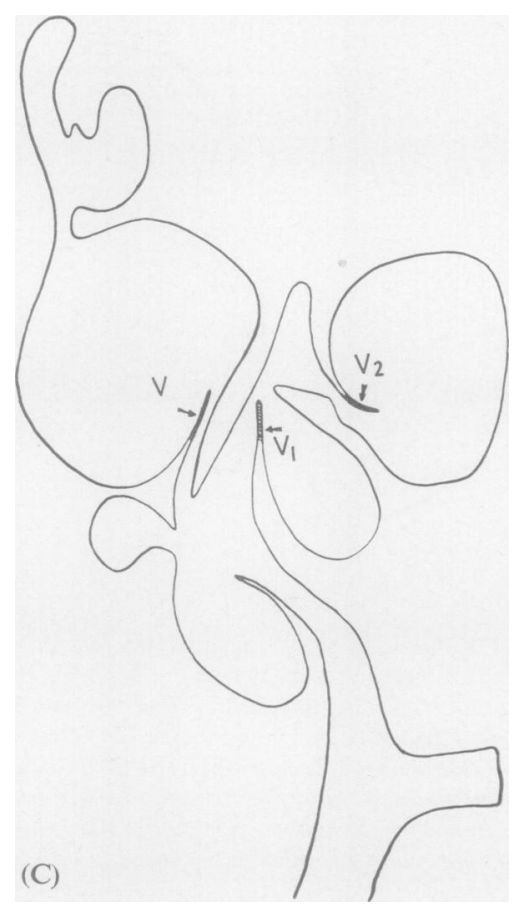

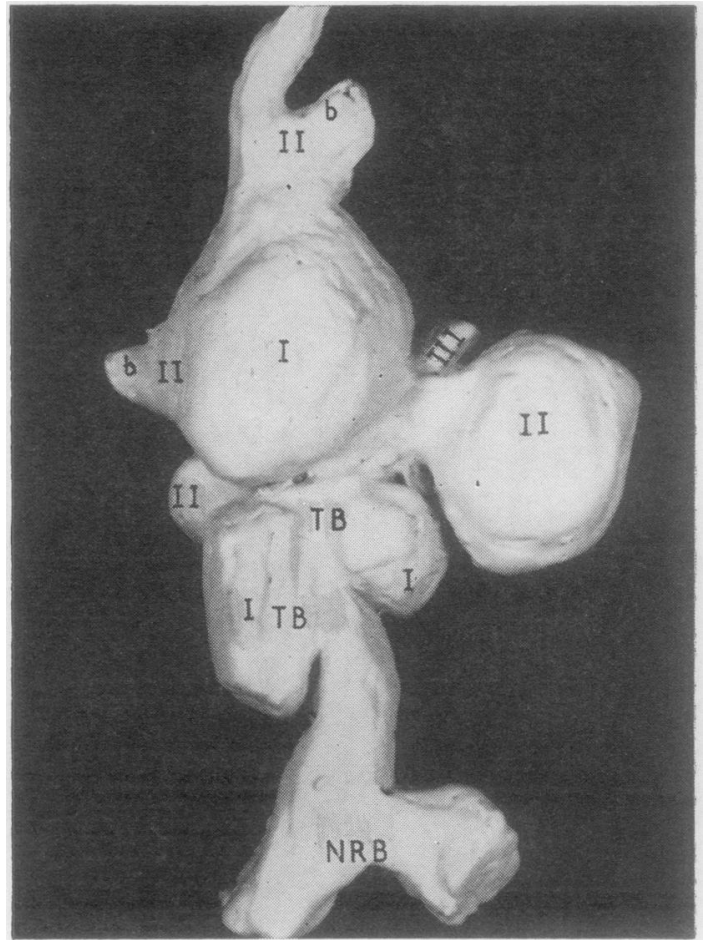

(B)

FIG. 5. (A) Part of a honeycomb lung in a case of

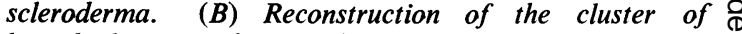
bronchiolar cysts shown in $(A) .(C) A$ diagrammatic plan of the 'positive' tridimensional reconstruction. Note the existence of various valve mechanisms $\left(V, V_{1}, V_{2}\right)$.

precision as the bronchiolar changes, not only because of the difficulties usually found in alveolar emphysema but also because we did not have adequate photographic enlargements. However, we found all transitions from complete obliteration of the ducts and alveoli by fibrous tissue to granulomatous infiltration of their walls. In the latter case, the alveolar ducts are frequently found to be distended and rigid, sometimes appearing as large sacs hanging from the bronchiolar walls. This is shown in Figure 2B.

\section{DISCUSSION}

The microscopic tridimensional features of honeycomb lung are well defined and characteristic and completely independent of the nature of the pulmonary condition they accompany. The lesions responsible for their appearance involve the whole lobular bronchiolar system, but are particularly marked at the level of the terminal and respiratory bronchioles. The changes are fundamentally diffuse, saccular, or cystic bronchiolar dilatations (Figs 1B, 2B, 3B, 4B, and 5B). We believe that the bullous appearance of the cysts in honeycomb 


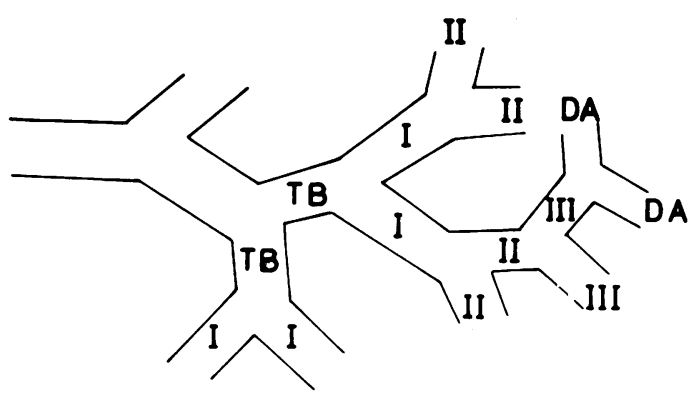

(A)
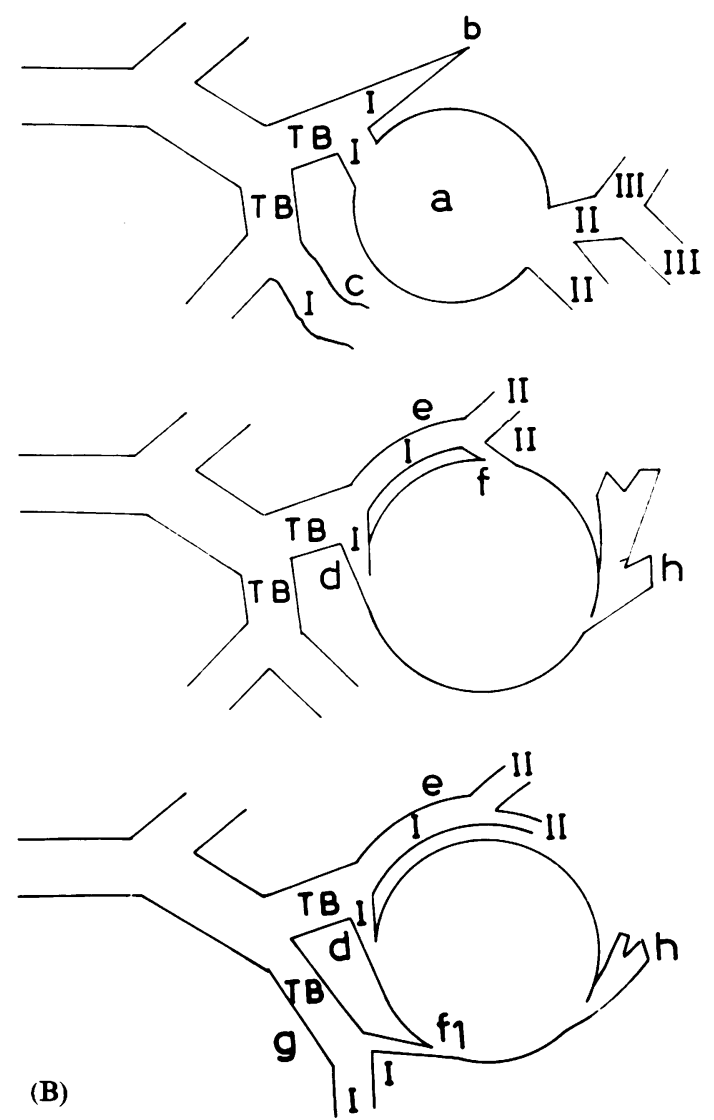

FIG. 6. Schematic representation of the more characteristic changes of the respiratory bronchioles in honeycomb lung found in our tridimensional models. $(A)$ Normal bronchiole. (B) Pathological changes. TB, terminal bronchiole; I, II, and III, first, second, and third respiratory bronchioles; $a$, dilatation (cyst); b, amputation; $c$, sinuous course; $d$, oblique disposition of the afferent bronchiole (probable valve mechanism); $e$, circular disposition of the bronchiole around the cyst; $f$ and $f_{1}$, various anastomoses; $g$, changes in direction; $h$, efferent bronchiole of the cyst. lung is due to the existence of a multiple valvular arrangement which develops along the distorted and dilated bronchioles (Figs 1C, 3B, 4C, 4D, and 5C). These permit the entrance of air but make its exit difficult. These valves are sometimes difficult to see in the usual histological serial sections and can only be identified in tridimensional reconstruction (Figs 1C, 3B, and 4C). In other instances, as Heppleston (1956) pointed out, they assume very characteristic appearances, and then the afferent bronchiole may be placed obliquely or tangentially in relation to the cysts (Figs $1 \mathrm{C}$, $3 \mathrm{~B}$, and $4 \mathrm{C}$ ). This is the most frequent, although not the only tridimensional aspect of the larger bullous cysts. Other bronchiolar changes are also found in honeycomb lung, such as changes in the direction and mode of division, amputations, and anastomoses between anatomically independent bronchioles (Figs 1B, 2B, 4B, and 5B). The latter finding is probably related to destruction of pulmonary parenchyma partly due to progressive distension of the cysts.

We believe that in the majority of cases the aetiology of honeycomb lung is related to the lesions so frequently associated with it that form the greater part of interstitial pulmonary fibrosis.

This close relationship between honeycomb lung and interstitial changes is also shown by the occasional findings of honeycombing near to localized pulmonary lesions accompanied by fibrosis or by a granulomatous process of the septa as one finds in cases of pulmonary tuberculoma and in endogenous lipoid pneumonia (tumour-like lipoid pneumonia) included in our material. We do not, however, agree with Heppleston's views that honeycombing is due to the compensatory dilatation of undiseased bronchioles adjacent to areas immobilized by interstitial fibrosis.

Our study shows that the lesions develop in bronchioles altered either by obliteration or by rigidity of the corresponding ducts and alveoli, or by the bronchiolar or peri-bronchiolar localization of some of the fibrosis of the alveolar interstitium. We believe that the various types of bronchiolar changes we have mentioned prove this point. However, for inflation of the valvular cysts to take place it is necessary that the surrounding parenchyma maintains sufficient expansibility.

Finally, one must bear in mind that the honeycomb lesions found in cases of muscular pulmonary cirrhosis are identical with those found in the other diseases (Figs 3A and B). This finding and the existence of cases of this disease unaccompanied by muscular proliferation (Pepere, 1906 ; Loeschcke, 1926) lead us to agree with other 
authors (Siebert and Fisher, 1957), who believe that this disease is only another form of progressive pulmonary fibrosis in which the proliferation of smooth muscle is especially well developed for reasons that we do not understand.

\section{REFERENCES}

Anderson, A. E., Jr., and Foraker, A. G. (1960). Morphological aspects of interstitial pulmonary fibrosis. Arch. Path., 70, 79.

Auld, D. (1957). Pathology of eosinophilic granuloma of the lung. Ibid., 63, 113 .

Buechner, H. A., and Anderson, A. E. (1955). Diffuse indolent pulmonary tuberculosis. Amer. Rev. Tuberc., 71, 503.

von Buhl, L. (1872). Lungenentzundung, Tuberkulose und Schwindsucht. Oldenbourg, Munich.

Delarue, J., Paillas, J., Paley, P., Daumet, Ph., and Daussy, M. (1960). Insuffisance respiratoire progressive, emphyseme bulleux et leiomyomatose pulmonaire diffuse. J. franç. Méd. Chir. thor. 14, 761.

Dutra, F. R. (1948). The pneumonitis and granulomatosis peculiar to beryllium workers. Amer.J. Path., $24,1137$.

González-Licea, A., and Perez-Tamayo, R. (1963). Idiopathic diffuse bronchiolectasis-so-called bronchiolar emphysema. Amer. J. clin. Path., 40, 157.

von Hayek, H. (1960). The Human Lung, trans. V. E. Krahl. Hafner, New York.

Heppleston, A. G. (1956). The pathology of honeycomb lung. Thorax, $11,77$.
Hyde, L., Hyde, B., and Pokorny, C. (1951). Diffuse fibrocystic disease of lungs (honey-comb lungs). Dis. Chest, 19, 190

Keats, T. E., and Crane, J. F. (1954). Cystic changes of the lungs in histiocytosis. Amer. J. Dis. Child., 88, 764.

Loeschcke, H. (1926). Emphysema bronchiolektaticum und pràterminale Bronchiektasen als Systemerkrankungen isolierter Abschnitte des Bronchialbaumes. Verh. dsch. path. Ges., 21, 242.

Mahrer, P. R., Evans, J. A., and Steinberg, I. (1954). Scleroderma: § relation of pulmonary changes to esophageal disease. Ann. intern. Med., 40, 92.

Miller, W. S. (1947). The Lung, 2nd ed. Thomas, Springfield, Illinois.

Mills, E. S., and Mathews, W. H. (1956). Interstitial pneumonitis in dermatomyositis. J. Amer. med. Ass., 160, 1467.

Nickerson, D. A. (1937). Boeck's sarcoid. Report of six cases in which autopsies were made. Arch. Path., 24, 19.

Peabody, J. W., Jr., Buechner, H. A., and Anderson, A. E. (1953). Hamman-Rich syndrome. Arch. intern. Med., 92, 806

Pepere, A. (1906). Della degenerazione cistica del polmone. Sperimentale, 60,171 .

Pimentel, J. C. (1962). Aspectos morfológicos da 'fibrose pulmonar' J. Méd. (Pôrto), 49, 823.

Rubenstein, L., Gutstein, W. H., and Lepow, H. (1955). Pulmonary muscular hyperplasia (muscular cirrhosis of the lungs). $A n n$. intern. Med., 42, 36.

Rubin, E. H. (1955). Pulmonary lesions in 'rheumatoid disease' with $C$ remarks on diffuse interstitial pulmonary fibrosis. Amer. J. Med.. $\mathbb{D}$ 19,569 .

Siebert, F. T., and Fisher, E. R. (1957). Bronchiolar emphysema. Socalled muscular cirrhosis of the lungs. Amer. J. Path., 33, 1137.

Telischi, M., and Rubenstone, A. I. (1961). Pulmonary asbestosis. Arch. Path., 72, 234.

van Creveld, S., and ter Poorten, F. H. (1935). Infective reticuloendotheliosis chiefly localized in lungs. bone marrow and thymus. Arch. Dis. Childh., 10, 125. 